\title{
PENGEMBALIAN SAHAM, RISIKO PASAR, DAN SENTIMEN
}

\author{
Winston Pontoh ${ }^{1}$ \\ ${ }^{1}$ Program Studi Pendidikan Profesi Akuntansi, Fakultas Ekonomi dan Bisnis, Universitas Sam Ratulangi, Jl. \\ Kampus Bahu, Manado, 95115, Indonesia \\ E-mail : winstonpontoh@unsrat.ac.id
}

\begin{abstract}
The relationship between stock returns, risk, and investor sentiments still a debate in the field of finance and accounting. Most of researchers find different results for relationship between stock returns, risk, and investor sentiments. This study conducts logistic regression to analyze the relationship of market risk and investor sentiments on stock returns of 146 Indonesian public firms as dividend payers along period of 2010 to 2016. This study finds that along period of 2010 to 2016 most of stock returns are affected by investor sentiments. This study also finds that market risk does not affect the stock returns since this study reveals that market risk between higher and lower stock returns have not differences.
\end{abstract}

Keywords : stock returns, market risk, sentiment, investors

\section{PENDAHULUAN}

Permasalahan pengembalian saham (stock returns) masih merupakan topik yang masih diperdebatkan dalam bidang akuntansi dan keuangan. Hal ini disebabkan karena masih terdapat hubungan antara pengembalian saham dengan masalah risiko pasar (market risk) dan sentimen investor (sentiment) dalam pasar modal, khususnya di Indonesia yang masih merupakan sebuah pasar yang baru (emerging market).

Hasil penelitian dari Aliu et al. (2017), dan Hasan et al. (2012) menunjukkan hubungan antara pengembalian saham dan risiko, khususnya yang terkait dengan risiko pasar. Beberapa hasil penelitian lainnya seperti Changsheng \& Yongfeng (2012), dan Uygur \& Tas (2014) menunjukkan bahwa terdapat peran dari sentimen investor atas pergerakan harga saham dalam pasar modal yang menyebabkan terjadinya perubahan atas pengembalian saham. Penelitian ini bertujuan untuk memberikan bukti empiris atas dampak risiko pasar dan sentimen investor atas pengembalian saham dalam pasar modal di Indonesia.

\section{TINJAUAN PUSTAKA}

\subsection{Pengembalian saham dan risiko}

Maheu \& McCurdy (2007) menemukan bahwa hubungan risiko dan pengembalian saham adalah positif khususnya pada perusahaan-perusahaan industri di Amerika Serikat. Hunjra et al. (2011) menunjukkan bahwa terdapat pengaruh positif atas risiko terhadap pengembalian saham di Bursa Efek Karachi di Pakistan. Premkanth (2012) juga menemukan bahwa risiko secara positif mempengaruhi pengembalian saham pada perusahaan-perusahaan di Sri Lanka. Bora \& Adhikary (2015) pada penelitian atas perusahaan-perusahaan terbuka di India menemukan bahwa risiko memiliki hubungan positif dengan pengembalian saham walaupun cenderung tidak stabil. Hasil serupa ditemukan oleh Aliu et al. (2017) pada perusahaan-perusahaan penyedia (supplier) terbuka di Czech, dimana risiko akan meningkatkan pengembalian saham. Sebaliknya, Hasan et al. (2012) menemukan bahwa tidak terdapat hubungan antara risiko dan pengembalian saham khususnya pada perusahaanperusahaan terbuka di Bursa Efek Dhaka, Bangladesh. Hasil serupa juga ditemukan oleh Ferson \& Harvey (1994), dimana risiko pasar (beta pasar) pada beberapa negara di dunia tidak cukup signifikan dalam menjelaskan pengembalian saham. 


\subsection{Pengembalian saham dan sentimen}

Changsheng \& Yongfeng (2012) menunjukkan bahwa dalam pasar modal di China, sentimen memiliki pengaruh signifikan dan positif dalam menjelaskan perubahan-perubahan pengembalian saham. Sebaliknya, Yoshinaga \& de Castro Junior (2012) menemukan bahwa sentimen memiliki hubungan negatif signifikan atas pengembalian saham di pasar modal Brazil. Rahman et al. (2013) juga menemukan bahwa terdapat hubungan positif dan pengembalian saham di negata Bangladesh. Hasil serupa ditemukan oleh Uygur \& Tas (2014) dalam penelitian di Bursa Efek Istanbul, bahwa sentimen investor memiliki peran positif dalam mempengaruhi pengembalian saham. Huang et al. (2014) menemukan bahwa sentimen memiliki pengaruh positif pada periode saat terjadinya pergerakan saham yang berdampak pada pengembalian saham. Oprea \& Brad (2014) menemukan bahwa sentimen investor pada Bursa Efek Bucharest di Romania hanya akan mempengaruhi saham-saham yang bernilai rendah sedangkan saham-saham bernilai tinggi tidak akan dipengaruhi secara signifikan. Junwen \& Xinxin (2017) menemukan bahwa sentimen investor memiliki pengaruh signifikan dan positif atas pengembalian saham di Bursa Efek Shanghai.

\section{METODE PENELITIAN}

\subsection{Jenis dan sumber data}

Jenis data dalam penelitian ini adalah berbentuk data rasio dimana data-data tersebut diperoleh dari Bursa Efek Indonesia pada rentang periode 2010 sampai dengan tahun 2016.

\subsection{Sampel dan teknik pengambilan sampel}

Sampel dalam penelitian ini adalah 146 perusahaan terbuka, dengan kriteria sebagai berikut : (a) menerbitkan laporan audit tahunan; dan (b) memiliki pembayaran dividen ratarata diatas Rp. 0 selama periode pengamatan.

\subsection{Metode analisis}

Penelitian ini menggunakan analisis regresi logistik, dimana variabel dependen adalah pengembalian saham. Pengembalian saham diukur dengan menggunakan dummy dimana pengembalian saham tertinggi (kode 1) akan berada diatas nilai median sedangkan pengembalian terendah (kode 0) akan berada dibawah atau sama dengan nilai median. Variabel independen untuk penelitian ini adalah sebagai berikut :

1. Risiko pasar (RP), diukur dengan menggunakan beta saham dari Capital Asset Pricing Model (CAPM) menurut Sharpe (1964) dan Lintner (1965) dengan model berikut :

$\mathrm{R}_{\mathrm{it}}-\mathrm{RF}_{\mathrm{t}}=\alpha_{\mathrm{i}}+\beta\left(\mathrm{RM}_{\mathrm{t}}-\mathrm{RF}_{\mathrm{t}}\right)+\varepsilon_{\mathrm{it}}$

dimana, $\mathrm{R}_{\mathrm{it}}$ adalah pengembalian saham perusahaan i pada periode $\mathrm{t}, \mathrm{RF}_{\mathrm{t}}$ adalah risk free atau tingkat pengembalian bebas risiko berdasarkan suku bunga Bank Indonesia periode $t$, dan $\mathrm{RM}_{\mathrm{t}}$ adalah pengembalian pasar (market return) pada periode $\mathrm{t}$.

2. Sentimen (S), diukur dengan menggunakan Individual Stock Return dari Liao et al. (2012), dengan rumus berikut :

$\log \left(\mathrm{P}_{\mathrm{i}, \mathrm{t}}\right)-\log \left(\mathrm{P}_{\mathrm{i}, \mathrm{t}-1}\right)$

dimana, $\mathrm{P}_{\text {it }}$ adalah harga saham penutupan perusahaan i pada akhir periode $\mathrm{t}$.

Model persamaan yang digunakan dalam penelitian ini adalah sebagai berikut :

$\mathrm{R}=\alpha+\beta \mathrm{RP}+\beta \mathrm{S}+\varepsilon$

\section{HASIL ANALISIS DAN PEMBAHASAN}

\subsection{Hasil analisis}

Tabel 1 menunjukkan statistik deskriptif atas risiko pasar (RP) dan sentimen (S). Nilai rata-rata (mean) risiko pasar untuk pengembalian saham tertinggi adalah lebih tinggi dari nilai rata-rata (mean) risiko pasar untuk pengembalian saham yang rendah. Hasil ini mengindikasikan bahwa saham-saham yang memiliki pengembalian yang tinggi cenderung memiliki risiko pasar yang tinggi (lebih berisiko) dibandingkan dengan saham-saham yang 
memiliki pengembalian yang rendah. Akan tetapi, berdasarkan hasil uji beda, kedua nilai mean ternyata tidak memiliki perbedaan yang signifikan, sehingga dapat disimpulkan bahwa risiko pasar untuk saham-saham dengan pengembalian tinggi adalah sama dengan sahamsaham dengan pengembalian rendah.

Tabel 1 juga menunjukkan bahwa nilai mean sentimen untuk saham-saham dengan pengembalian yang tinggi lebih tinggi dibandingkan nilai mean sentimen untuk saham-saham dengan pengembalian yang rendah. Hal ini mengindikasikan bahwa investor cenderung lebih cepat bereaksi atas saham-saham yang memiliki pengembalian yang tinggi dibandingkan dengan saham-saham dengan pengembalian yang rendah. Hasil uji beda menunjukkan bahwa selisih kedua nilai mean adalah signifikan sehingga hasil ini sekaligus mengkonfirmasikan statistik deskriptif.

Tabel 1. Statistik deskriptif

\begin{tabular}{|c|c|c|c|c|c|c|c|}
\hline \multirow{2}{*}{ Variabel } & \multicolumn{3}{|c|}{ Pengembalian tertinggi } & \multicolumn{3}{|c|}{ Pengembalian terendah } & \multirow{2}{*}{ Uji Beda } \\
\hline & Min. & Max. & Mean & Min. & Max. & Mean & \\
\hline $\mathrm{RP}$ & -13.19 & 16.58 & 0.7744 & -4.06 & 4.43 & 0.7010 & 0.07348 \\
\hline $\mathrm{S}$ & -2.00 & 1.65 & 0.0626 & -1.88 & 0.81 & -0.0338 & $0.09643 * * *$ \\
\hline \multicolumn{8}{|c|}{ 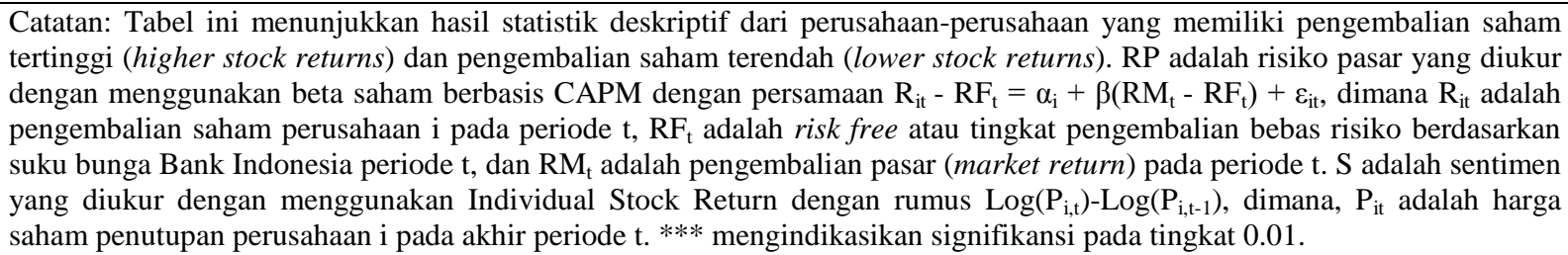 } \\
\hline
\end{tabular}

Guna mengetahui dampak dari kedua variabel ini atas pengembalian saham (stock returns), maka penelitian ini melanjutkan analisis dengan menggunakan regresi logistik. Berdasarkan hasil analisis regresi logistik yang tidak dicantumkan, nilai chi-square atas ketiga model yang dianalisis adalah tidak signifikan pada 5\% sehingga disimpulkan bahwa model adalah fit.

Tabel 2. Uji regresi logistik

\begin{tabular}{lrrr}
\hline \multicolumn{1}{c}{ Variabel independen } & Model 1 & \multicolumn{1}{c}{ Model 2 } & \multicolumn{1}{c}{ Model 3 } \\
\hline Intercept & -0.019 & -0.021 & -0.048 \\
RP & 0.026 & & 0.036 \\
S & & $1.269 * * *$ & $1.277^{* * *}$ \\
Pseudo R-square & 0.001 & 0.038 & 0.039 \\
\hline
\end{tabular}

Catatan: Tabel ini menunjukkan hasil uji regresi logistik dari perusahaan-perusahaan yang memiliki pengembalian saham tertinggi (higher stock returns) dan pengembalian saham terendah (lower stock returns), dimana referensi yang digunakan adalah saham-saham dengan pengembalian rendah. RP adalah risiko pasar yang diukur dengan menggunakan beta saham berbasis CAPM dengan persamaan $R_{i t}-R F_{t}=\alpha_{i}+\beta\left(R_{t}-R F_{t}\right)+\varepsilon_{i t}$, dimana $R_{i t}$ adalah pengembalian saham perusahaan i pada periode $\mathrm{t}, \mathrm{RF}_{\mathrm{t}}$ adalah risk free atau tingkat pengembalian bebas risiko berdasarkan suku bunga Bank Indonesia periode $\mathrm{t}$, dan $\mathrm{RM}_{\mathrm{t}}$ adalah pengembalian pasar (market return) pada periode $\mathrm{t}$. $\mathrm{S}$ adalah sentimen yang diukur dengan menggunakan Individual Stock Return dengan rumus $\log \left(\mathrm{P}_{\mathrm{i}, \mathrm{t}}\right)-\log \left(\mathrm{P}_{\mathrm{i}, \mathrm{t}-1}\right)$, dimana, $\mathrm{P}_{\mathrm{it}}$ adalah harga saham penutupan perusahaan i pada akhir periode t. $* * *$ mengindikasikan signifikansi pada tingkat 0.01 .

Tabel 2 menunjukkan bahwa risiko pasar (RP) dalam Model 1 (tanpa variabel sentimen) tidak memiliki pengaruh signifikan atas pengembalian saham. Nilai R-square sebesar 0.001 atau sebesar $0.1 \%$ mengindikasikan bahwa variabel risiko pasar cukup kecil dalam menjelaskan model pengembalian saham. Apabila menggunakan variabel sentimen tanpa mengikutsertakan variabel risiko pasar (Model 2), maka Tabel 2 menunjukkan bahwa variabel sentimen adalah signifikan dan positif dalam mempengaruhi pengembalian saham. Hasil ini mengindikasikan bahwa terjadinya peningkatan sentimen oleh investor akan meningkatkan pengembalian saham khususnya untuk saham-saham dengan pengembalian tinggi. Nilai R-square dari Model 2 juga memiliki nilai yang lebih baik yaitu sebesar 0.038 
sehingga mengindikasikan bahwa variabel sentimen cukup menjelaskan model dari pengembalian saham. Tabel 2 menunjukkan bahwa hasil analisis pada Model 3 menguatkan hasil dari Model 2 untuk variabel sentimen, dimana variabel ini secara konstan signifikan dan positif dalam mempengaruhi pengembalian saham. Nilai R-square juga mengalami peningkatan setelah melibatkan variabel risiko pasar dan sentimen yaitu sebesar 0.039.

\subsection{Pembahasan}

Hasil uji dalam Model 1 menunjukkan bahwa hasil dari penelitian ini tidak mendukung hasil penelitian dari Maheu \& McCurdy (2007), Hunjra et al. (2011), Premkanth (2012), Bora \& Adhikary (2015), dan Aliu et al. (2017). Akan tetapi, hasil penelitian ini konsisten dengan hasil penelitian dari Hasan et al. (2012), dan Ferson \& Harvey (1994). Sedangkan untuk hasil uji pada Model 2, penelitian ini cukup konsisten dengan hasil-hasil penelitian dari Changsheng \& Yongfeng (2012), Rahman et al. (2013), Uygur \& Tas (2014), Huang et al. (2014), dan Junwen \& Xinxin (2017) walaupun tidak konsisten dengan hasil penelitian dari Yoshinaga \& de Castro Junior (2012), dan Oprea \& Brad (2014).

Hasil uji untuk Model 3 mempertegas hasil dari kedua model (Model 1 dan Model 2) sehingga hasil penelitian ini memberikan bukti empiris bahwa dalam pasar modal di Indonesia, faktor sentimen investor akan sangat berperan dalam pembentukan pengembalian saham (stock returns). Hasil penelitian ini juga memberikan bukti empiris bahwa risiko pasar dalam rentang periode 2010 sampai dengan tahun 2016 tidak cukup mempengaruhi pergerakan harga pasar saham yang berdampak pada pembentukan pengembalian saham.

\section{KESIMPULAN DAN SARAN}

\subsection{Kesimpulan}

Berdasarkan hasil pengujian atas model penelitian, maka kesimpulan dalam penelitian ini adalah :

1. Risiko pasar tidak mempengaruhi secara signifikan atas pergerakan harga saham dalam pembentukan pengembalian saham dalam rentang periode 2010 hingga 2016.

2. Sentimen investor secara empiris dapat mempengaruhi pergerakan harga saham secara signifikan yang berdampak pada meningkatnya pengembalian saham dalam rentang periode 2010 hingga 2016.

\subsection{Saran}

Berdasarkan hasil penelitian, maka saran dari penelitian ini agar pada penelitian selanjutnya dapat memperluas kajian hingga total pengembalian saham (total returns). Selain itu, peneliti selanjutnya diharapkan memperluas rentang periode pengamatan dari penelitian ini. Penelitian selanjutnya juga diharapkan untuk mengkaji perusahaan-perusahaan terbuka yang tidak membayar dividen.

\section{DAFTAR PUSTAKA}

Aliu, F., Pavelkova, D., \& Dehning, B. (2017). Portfolio risk-return analysis: The case of the automotive industry in the Czech Republic. Journal of International Studies, 10(4), 72-83. doi:10.14254/2071-8330.2017/10-4/5

Bora, B., \& Adhikary, A. (2015). Risk and return relationship - An empirical study of bse sensex companies in India. Universal Journal of Accounting and Finance, 3(2), 45-51. doi : 10.13189/ujaf.2015.030203

Changsheng, Hu, \& Yongfeng, W. (2012). Investor sentiment and assets valuation. Systems Engineering Procedia 3, 166-171. doi:10.1016/j.sepro.2011.11.023

Ferson, W. E., \& Harvey, C. R. (1994). Sources of risk and expected returns in global equity markets. Journal of Banking and Finance, 18, 775-803. 
Hasan, M. Z., Kamil, A. A., Mustafa, A., \& Baten, M. A. (2012). Relationship between risk and expected returns : Evidence from the Dhaka Stock Exchange. Procedia Economics and Finance, 2, 1-8. doi : 10.1016/S2212-5671(12)00058-5.

Huang, C., Yang, X., Yang, X., \& Sheng, H. (2014). An Empirical Study of the Effect of Investor Sentiment on Returns of Different Industries. Mathematical Problems in Engineering, 2014. http://dx.doi.org/10.1155/2014/545723

Hunjra, A. I., Azam, M., Niazi, G. S. K., Butt, B. Z., Rehman, K., \& Azam, R. (2011). Risk and Return Relationship in Stock Market and Commodity Prices: A Comprehensive Study of Pakistani Markets. World Applied Sciences Journal, 13(3), 470-481.

Junwen, F., \& Xinxin, L. (2017). Investor sentiment and stock return: Evidence from Chinese stock market. Biotechnology Indian Journal, 13(1), 123.

Liao, T.-L., Huang, C.-J., \& Wu, C.-Y. (2012). Empirical study : Do fund managers herd to counter investor sentiment? Principal Component Analysis - Multidisciplinary Applications. https://doi. org/10.5772/38510

Lintner, J. (1965). The valuation of risk assets and the selection of risky investments in stock portfolios and capital budgets. The Review of Economics and Statistics, 47(1), 13-37. https://doi.org/10.2307/1924119

Maheu, J. M., \& McCurdy, T. H. (2007). Components of market risk and return. Journal of Financial Econometrics, 5(4), 560-590. doi:10.1093/jjfinec/nbm012

Oprea, D. Ș., \& Brad, L. (2014). Investor Sentiment and Stock Returns: Evidence from Romania. International Journal of Academic Research in Accounting, Finance and Management Sciences, 4(2), 23-29. doi: 10.6007/IJARAFMS/v4-i2/764

Premkanth, P. (2012). Risk analysis and its impact on return: a study on manufacturing companies in Sri Lanka. Basic Research Journal of Business Management and Accounts, 1(5), 78-83.

Rahman, M. A., Shien, L. K., \& Sadique, M. S. (2013). Swings in sentiment and stock returns: Evidence from a frontier market. International Journal of Trade, Economics and Finance, 4(6), 347-352. doi : 10.7763/IJTEF.2013.V4.315

Sharpe, W. F. (1964). Capital asset prices: A theory of market equilibrium under conditions of risk. The Journal of Finance, 19(3), 425-442. https://doi.org/10.2307/2977928

Uygur, U., \& Tas, O. (2014). The impacts of investor sentiment on different economic sectors: Evidence from Istanbul Stock Exchange. Borsa Istanbul Review, 14(4), 236241. http://dx.doi.org/10.1016/j.bir.2014.08.001

Yoshinaga, C. E., \& de Castro Junior, F. H. F. (2012). The relationship between market sentiment index and stock rates of return: A panel data analysis. Brazillian Administration Review, 9(2), 189-210. 